\title{
2nd International Conference on the Elimination of Leprosy, New Delhi, India, 11-13 October 1996
}

\section{Recommendations}

The Second International Conference on the Elimination of Leprosy, convened on the initiative of the World Health Organization in New Delhi, India, from 11 to 13 October 1996, mindful of the commitment of all Member States of WHO, under World Health Assembly Resolution WHA44.9, of 1991, 'to continue to promote the use of all control measures including Multidrug Therapy (MDT) together with case-finding in order to attain the global elimination of leprosy as a public health problem by the year 2000', endorses the updated WHO global strategy and the intensified plan of action, and RECOMMENDS that:

- All parties concerned-national governments, nongovernmental organizations and international agencies - should recognize the unprecedented opportunity available now to reach the goal of eliminating leprosy as a public health problem, particularly in the light of the remarkable progress made so far, and that they intensify their political commitment and efforts to reach the remaining patients before the year 2000, bearing in mind that there is no room for complacency if the goal is to be attained.

- The remaining problem of leprosy treatment will be far more difficult as it includes hitherto neglected areas, population groups and communities. It is important that programme managers develop special intensive operations to reach them through such mechanisms as leprosy elimination campaigns (LEC) to detect hidden cases and special action projects (SAPEL) to reach difficult-to-access patients among under-served population groups such as nomads, refugees, migrants, etc.

- Ministries of Health in endemic countries should take immediate steps to further involve health personnel from the general health services in the treatment of leprosy patients, as well as in case-detection, so that these activities are adequately integrated into the general health services. Even as integration within the general health services is achieved, the quality of services provided to patients should be assured.

- As the technology employed to reach the leprosy elimination goal is essentially through the treatment of patients with multidrug therapy (MDT), it is extremely important that the free supply of WHO recommended MDT drugs in blister packs to patients be continued without interruption to ensure every patient has access to MDT.

- In order to ensure that all patients have access to MDT and that the progress being made towards leprosy elimination can be accurately assessed, the special initiative of leprosy monitoring (LEM) should be implemented as soon as possible.

- In view of the continued social problems faced by persons affected by leprosy, it is highly important to further intensify our efforts at creating community awareness of the disease and its curability, and to mobilize community action towards the elimination of leprosy. It is important that persons affected by leprosy be actively involved as partners in this process. 
- Even as leprosy patients are being cured of the disease, many of them continue to face problems in rehabilitating and reintegrating themselves within their communities, and consequently every attempt should be made to bring persons disabled due to leprosy and their rehabilitation within the general ambit of all disabled in the community and within existing community-based rehabilitation programmes.

- At this critical stage in the progress being made towards reaching the target, there is an urgent need for all to step up the coordination and mobilization of the resources neededfinance, manpower and planning for the future. This is particularly important for all partners, including governments, international donors and nongovernmental organizations.

- It is important that research activities in leprosy be continued, especially with regard to the operational aspects, chemotherapy and treatment of complications of leprosy. The understanding of the basic biological mechanisms of this disease is important for developing potential tools that may lead to eventual eradication.

- Countries, as they reach the elimination goal at the national level, should focus their attention on the target of elimination at the subnational levels, and sustain leprosy treatment and rehabilitation activities. It is important to ensure that services are capable of continuing to detect and treat new cases, and to respond to physical and social needs faced by individuals who have been affected by the disease. The efforts to ensure elimination as a public health problem will lay the foundation for our ultimate vision of the total eradication of leprosy in the future.

\section{SHORT REPORT ON THE SECOND INTERNATIONAL CONFERENCE ON ELIMINATION OF LEPROSY in New Delhi, India, held in October 1996}

Following the resolution of the World Health Assembly in 1991 that leprosy should be eliminated as a public health problem by AD 2000, the WHO launched a global drive to mobilize support and political commitment to achieve this goal. A first International Conference on Leprosy Elimination was held in Hanoi in 1994.

The Second International Conference was held in New Delhi, 1996. Its purpose was to maintain and, where possible, further strengthen the political and technical commitment in the top 24 leprosy-endemic countries to achieve the elimination goal by the turn of the century. To this extent, the Ministers of Health and Leprosy Control Programme Directors of the respective countries were invited to this high profile conference. Among the dignitaries present for some or all of the Conference were the Honourable Prime Minister of India, Mr H. D. Deve Gowda, the President of the Sasakawa Foundation, Japan, Mr Yohei Sasakawa, and the Director General of the WHO, Dr H. Nakajima. Other participants included senior representatives of ILEP member organizations, experts on leprosy and representatives from other organizations active in the field of leprosy, such as the International Leprosy Union (ILU) and IDEA. The latter is an international organization of persons affected by leprosy working on advocacy of the rights and needs of people disadvantaged in any way by the disease.

The theme of the conference was 'Reaching every patient in every village'. Country progress reports were presented by the respective Directors. This showed an invariable decline in the registered prevalence of leprosy, which was quite often not yet matched with a reduction in the case-detection rate. Overall, the MDT coverage of patients on treatment had improved dramatically in the last few years, with several countries having already reached $100 \%$. The main reasons for patients remaining undetected or not having access to MDT included remoteness of villages and difficult terrain, lack of motivation or involvement of 
peripheral health workers, migration and civil unrest, and war. Some, but not all of these problems can be overcome by carrying out Special Action Programmes for the Elimination of Leprosy (SAPEL) and/or Leprosy Elimination Campaigns (LEC). Reports on successful SAPEL and LEC campaigns, and lessons learned so far, were presented.

The International Leprosy Association (ILA), ILEP, ILU and World Bank presented their policies and programmes regarding leprosy control. Compared with earlier conferences of this nature, there was a much greater emphasis on what was called 'the human face of leprosy'. The presentations and the final recommendations of the conference highlighted the importance of prevention and treatment of impairments, disabilities and handicaps, "normalization of lives' of persons affected by the disease through rehabilitation and community awareness and participation. The latter was considered essential to achieve not only a medical but also a 'social elimination of leprosy as a public health problem'.

Four working groups of conference participants outlined priorities in important areas such as acceleration of leprosy elimination efforts at country level, reaching patients under difficult circumstances, monitoring and evaluation, and quality patient care and community action for leprosy elimination and rehabilitation. One highlight in the resulting recommendations was to advocate a global change of terminology when talking or writing about 'leprosy patients'. The use of this term should be restricted to the medical context of a health worker-patient relationship. In all other situations, when referring to a person and when his/her association with leprosy needs mentioning, the preferred term is a 'PERSON AFFECTED BY LEPROSY'. Referring to the association with leprosy is often not necessary: one does not for example talk about 'a gallbladder patient' when referring to a member of staff who has had his gallbladder removed. In many rehabilitation situations, a description such as 'a person with disability' will be sufficient. It was felt that such a change of terminology, if applied consistently, would greatly help to reduce the stigma against persons affected by leprosy and thus help towards the social elimination of leprosy.

While the longer-term benefits of this Conference are still awaited, it seemed very successful in increasing the interest and motivation among the senior country representatives present to work on a national level towards eliminating leprosy. With this increased political will and commitment, overcoming the many hurdles that still lie on the path of leprosy elimination may well be possible.

Director, INF Leprosy Project

DR WIM H. VAN BRAKEL

P.O. Box 5

Pokhara

Nepal

Fax: +9776121083/24515

E-mail: brakel@npl.healthnet.org

\section{Statement on behalf of The International Federation of Anti-Leprosy Associations (ILEP)}

Dear Friends and Colleagues

On behalf of the 20 member-associations of ILEP, several of whom are themselves represented here, I welcome this opportunity to outline the current concerns and initiatives of our Federation. 
WHAT IS ILEP?

As most of you know, ILEP brings together all the main non-governmental donor agencies interested in leprosy. For them the meetings and information services of ILEP are the means to co-ordinate the support they are giving to a thousand field and research projects in a hundred and one countries.

Despite the difficult fundraising conditions of recent years, ILEP Members have been able to budget $\$ 65.5$ million for support of projects in 1996. Furthermore, at the end of 1995 projects supported by member-associations were providing chemotherapy to 450,000 patients or $49 \%$ of the world total of registered patients.

We believe these are impressive achievements for voluntary organizations. There can be few other health areas where the contribution of the non-governmental sector is so significant. And, of course, while I speak for the donor agencies who come together in ILEP, the contribution of local NGOs in endemic countries must also be recognized. It is often their activities which are supported by ILEP Members. They, as well as National Programmes, are our partners in the field.

\section{A COMMITMENT TO LEPROSY}

The other important introductory point I would like to make is that ILEP and its member associations have a long-term commitment to work against leprosy and to respond to the needs of the individuals who have been affected by the disease.

The nature of leprosy work is changing and some of us see linkages with other health programmes such as tuberculosis as an effective way to ensure the continuance of antileprosy activity under conditions of low endemicity.

Nonetheless, it is clear from a survey of member-associations last year that the great majority of us are committed to anti-leprosy work as our main concern for the foreseeable future.

ILEP Members expect to be supporting work connected with leprosy well into the next century.

THE LONG-TERM CHALLENGE

In this Conference we are discussing Elimination of Leprosy as a Public Health Problem by the Year 2000. We have today heard encouraging reports of progress. The prevalence target of 1 per 10,000 looks likely to be reached in many countries albeit with some gaps.

ILEP member-associations with our own target of MDT for All have long supported and recognized the importance of this achievement. It is a major step on the road. It means that in many areas leprosy will have been brought under control in public health terms.

But, as my predecessor, Tom Frist explained at the Conference in Hanoi in 1994, in ILEP we believe that there is a great deal more to be done.

Effective implementation of multidrug therapy is not the end of the leprosy story. Our eventual aim must be to truly eradicate this disease. But we do not yet have the tools to do it.

Beyond the year 2000 there remains considerable work to be pursued and on which I hope we will all be able to collaborate:

- Responding to the social and physical disadvantages suffered by many who have had the disease. 
- Ensuring new cases continue to be detected and treated, and that there is no resurgence of the disease.

- Seeking the tools and strategies which one day will permit us to really eradicate Mycobacterium leprae.

With these concerns in mind, ILEP member-associations at their General Assembly in June this year adopted a statement of priorities for our Federation over the next few years. I believe it encompasses much of our view of what is important in leprosy-related activity today; so I want to read it to you in full.

ILEP and its member-associations are determined to respond to the total and continuing problem of leprosy. The priority of the Federation, therefore, over the next few years is to assist Members as effectively as possible to achieve:

- Prevention of Disabilities for all people affected by leprosy.

- MDT for All who need it.

- Health services capable of sustaining cost-effective anti-leprosy activities under conditions of low endemicity.

- Normalization of the lives of all people who are or have been affected by leprosy. Normalization covers both physical and social rehabilitation.

- Continuation of essential research into leprosy, especially as regards the development of tools for prevention of the disease, ever more efficient treatment, and the prevention of disability.

For each of the topics touched on in this statement of priorities, I would like to say some more about what ILEP is doing:

\section{Prevention of disabilities}

(a) It has often been said that any good leprosy control programme should include action for the prevention of disabilities. Practice, however, is often more difficult.

So this time last year ILEP undertook a survey of a random sample of projects to find out what they did and what constraints to PoD activity they faced. This was followed up by a workshop of invited experts, leading to the publication in December 1995 by our then Medical Commission of a set of recommendations for including simple and effective PoD activities in control programmes. These are available as a Medical Bulletin of ILEP.

I should say that we were not only telling others what they should do. One recommendation was aimed at our own Members because the survey showed we had failed to get our own detailed guide on PoD to $40 \%$ of our projects!

(b) There is a lack of data on the scale of the disability problem in leprosy. The only hard information regularly collected is whether a patient has Grade 2 disability at the point of diagnosis. On the basis of this, WHO estimated a year ago that there are around 2 million people with severe disabilities caused through leprosy.

While Grade 2 data is an indicator of the effectiveness of a programme's case detection, Grade I is an indicator of those individuals who are at risk of disability due to loss of sensation. If identified, they can learn self-care and be helped to avoid ever developing serious disability.

Following advice from our Medical Commission and field testing of several possibilities, we are about to modify the ILEP B Questionnaire and include a new question on Grade 
1 disability. We hope this will encourage projects to assess and record patients with Grade 1 disability as a matter of course, and take appropriate action.

\section{MDT for All who need it}

(a) By the end of 1995, 87\% of patients registered in ILEP-supported projects were receiving MDT. We had hoped to have reached $100 \%$ by now and we are happy that is indeed the case for most projects. The shortfall relates in effect to just a handful of projects and a couple of countries.

Furthermore, the figure of $\mathbf{9 6 . 5 \%}$ MDT coverage for newly-detected cases shows that for all practical purposes we can say MDT is now used as a matter of course in ILEP-supported projects.

As a result, reference to monotherapy will be removed from the ILEP B questionnaire to avoid any suggestion that it could be an alternative to MDT.

(b) Our target of MDT for All, however, was never intended to relate only to registered patients. We are very conscious that there remain many individuals who have leprosy but have not been detected.

Incidentally, we have some hesitation about the WHO estimate of 400,000 undetected cases. This seems to us to be a rather optimistically low figure. None of us can know for sure what is the reality but on the basis of experience and reports from programmes, we consider it more reasonable to think in terms of around one million undetected cases.

We do, however, very much welcome the new WHO target of Treatment for Every Patient in Every Village. That parallels our concern for Filling the Gaps.

We recognise the positive intentions of SAPEL projects - to get to hard-to-reach patients-and LEC campaigns to get to 'missing' patients in areas of long-standing leprosy control activity. Indeed, several ILEP member-associations have supported SAPEL and LEC initiatives in countries where they are active. We look forward to exploring further possibilities for collaboration in initiatives of this type.

(c) I am sure that we all aim to bring down the number of cases of leprosy as far and as rapidly as possible. In ILEP, therefore, we are especially interested in what is happening to incidence. The reduction achieved in prevalence is impressive-In ILEP we have seen very near a halving of our caseload in 10 years $(1985: 829,000 ; 1995: 449,000)$-but until the number of new cases also falls it is difficult to be sure that MDT has had the impact we all hope for of limiting transmission.

The ILEP figures for newly detected cases in projects supported by memberassociations show that we experienced a noticeable increase in numbers between 1991 and 1994. This may well have been due to operational reasons but as we have said at previous WHO meetings, it made it difficult for us to assume that incidence is indeed about to decline. However, the figures appear to have levelled out in the last couple of years. This is encouraging but still far from persuasive.

We welcome, therefore, any efforts that can be made to understand in greater depth what exactly is happening to new detections and how far changes in the numbers demonstrate a genuine drop in new infections.

\section{Sustaining anti-leprosy activities under conditions of low endemicity}

Even where the 1 per 10,000 target has been reached, new cases will continue to appear for 
the foreseeable future. And, of course, 1 per 10,000 of the global population would still mean around 500,000 cases worldwide.

It is thus essential that health services retain the capability to detect, diagnose and treat leprosy both for the individuals affected and to avoid any danger of a resurgence of the disease.

We see this as the next major organizational challenge in leprosy. Thus, only two weeks ago, we convened in Amsterdam with the help of the Royal Tropical Institute an expert workshop to develop guidance on the process of integrating and preparing health services to sustain leprosy-related activities once endemicity is low. I believe some of those who anticipated are here today. Thank you!

We expect that the Guidelines resulting from this exercise will be published early next year. They are aimed in the first instance at ILEP member-associations and the projects they support but I believe will be of particular importance also to those of you who are managers of national programmes.

\section{Normalization of the lives of all people affected by leprosy}

WHO tells us that some 8 million people have been cured with MDT over the past fourteen years. That is a wonderful success story but we must not forget that many of these individuals suffer social stigma or disability due to leprosy.

Indeed, a recent study by the GLRA/ALES office in Southern India found that out of 50,000 past patients followed up, $18 \%$ reported social discrimination against them because of leprosy even though they suffered no physical disability. A further $14 \%$ suffered both disability and discrimination.

As ILEP Members we believe ways must be found to ensure that all who suffer the social or physical affects of leprosy, even after completion of MDT treatment, should have access to appropriate social and medical services whether integrated or specialized. The purpose must be to help people affected by leprosy overcome whatever difficulties they face due to the disease so that their lives return to normal. We have taken a number of relevant steps recently:

(a) As ILEP member-associations we see a need for more expert advice in the social area. We decided in June, therefore, to expand what was our Medical Commission and turn it into a Medico-Social Commission with a slightly larger membership.

The seven members have had their first meeting and elected Dr Cairns Smith as their Chair. We now look forward to a new impetus in our thinking about both the medical and the social aspects of leprosy.

(b) I must also recommend to you the book Don't Treat me like I have Leprosy written by Tom Frist, my predecessor as President of ILEP, under the auspices of our then Action Group on Social Aspects. It is a very helpful explanation of the social issues faced by people affected by leprosy and of what can be done to overcome them. You can obtain copies from Talmilep at TLMI in London.

(c) A novel initiative for us is a campaign we are undertaking to explain to other international development NGOs what is happening in leprosy today. We are not asking them to support leprosy work. We do, however, want them to be aware of the needs of people affected by leprosy so that they will ask if the community and health development programmes they support are conscious of and open to people affected by leprosy. 
The leaflet we have prepared for this purpose is available from us here at the Conference, if you are interested.

\section{Continuation of essential research}

We have been most concerned at the disappearance of funding for research related to leprosy. Much support for research is inherent in government funding of institutions in Europe and America. That has been tailing off as they begin - we believe much too early-to think that leprosy is no longer a priority. That word 'elimination' does not always have a positive effect!

ILEP member-associations plan to spend $\$ 3.7$ million on research and scientific activity this year. That is helpful but does not replace the much larger sums involved in the basic salaries and buildings of research institutions.

This problem was discussed last year by both the Forum of medical advisers to ILEP member-associations and by the WHO Leprosy Elimination Advisory Group (LEAG). Since then the ILEP Medical Commission has developed advice for member-associations on what research areas are of particular importance today and seem reasonably feasible. Their advice took on board ideas from a WHO/Sasakawa consultation in Bangkok earlier this year.

In general, we believe it is essential that research continues, especially into the development of tools for:

- Prevention of leprosy.

- Yet simpler and more efficient treatment.

- Prevention of disability.

As regards prevention of leprosy, ILEP member-associations are proud to have been closely associated with the Karonga Prevention Study which reported a few months ago. The main source of funding for what is recognised to be one of the most careful vaccine studies ever undertaken, came from ILEP Members, led by LEPRA.

I leave detailed discussion of the results to others but it is fascinating to see the differential impact of BCG in this population of Northern Malawi as between leprosy and tuberculosis. I look forward to hearing more regarding the implications for leprosy control of the effectiveness shown by the study of a second BCG vaccination.

In closing I want to reiterate the determination of ILEP and its member-associations both to continue work in leprosy and to do so in partnership with WHO, governments and local NGOs. The slogan of my own association, the Damien Foundation Belgium, is To the End of the Challenge. The job for all of us is not over until the day, still in the unknown future, when leprosy has been completely eradicated.

DR JEAN-PIERRE SCHENKELAARS

President of ILEP 